\title{
Perioperative radiotherapy in the management of rectal cancer
}

\author{
Lars Påhlman MD PhD FRCS
}

L Påhlman. Perioperative radiotherapy in the management of rectal cancer. Can J Gastroenterol 2001;15(4):259-264. Surgery for rectal cancer has resulted in unacceptably high local failure rates, and substantial morbidity and mortality. In an attempt to reduce the high frequency of local recurrence, perioperative radiotherapy has been used extensively, alone or in combination with chemotherapy. The local recurrence rate has been reduced dramatically with the use of radiotherapy, and provided that the dose is high enough and given preoperatively, the reduction rate has been about $50 \%$. Despite that a higher dose is used in postoperative radiotherapy, the reduced recurrence rate is not that prominent. The reduced recurrence rate demonstrated after preoperative radiotherapy has a positive influence on survival, which has not been seen when radiotherapy is given postoperatively. However, when postoperative irradiation has been combined with chemotherapy, a survival benefit has been demonstrated. With modern radiation techniques, preoperative radiotherapy can be delivered without any substantial increase in postoperative mortality or morbidity, and a low rate of late toxicity, provided that the radiation technique is optimal. The main question is whether radiotherapy is necessary, provided that surgery is optimized. With standard surgery, the average local recurrence rate is $29 \%$ in all reported controlled trials. With optimal surgery, from institutional series, this figure is about $10 \%$. Other questions to be answered are whether superfractionated or standard fractionation should be used in radiotherapy and exactly to whom it should be given.

\section{Radiothérapie périopératoire pour le traitement du cancer du rectum}

RÉSUMÉ : Le traitement chirurgical du cancer du rectum s'est soldé par un taux inacceptable d'échecs, entraînant une morbidité et une mortalité élevées. Dans une tentative visant à réduire le taux élevé de récurrence locale, on a eu largement recours à la radiothérapie périopératoire, seule ou association avec la chimiothérapie. La mesure s'est traduite par une diminution spectaculaire de ce taux, de l'ordre de $50 \%$, pourvu que la dose soit suffisamment forte et qu'elle soit administrée en phase préopératoire. En effet, la radiothérapie en phase postopératoire, malgré l'administration de doses plus fortes, ne donne pas de résultats aussi remarquables. La radiothérapie préopératoire a une incidence favorable sur la survie, ce qui n'est pas le cas de la radiothérapie postopératoire. Toutefois, on a observé une amélioration du taux de survie lorsque la radiothérapie postopératoire est administrée en association avec la chimiothérapie. Aujourd'hui, grâce aux techniques modernes de rayonnement, et ce, à condition qu'elles soient optimales, la radiothérapie préopératoire peut être administrée sans entraîner d'augmentation significative de la morbidité et de la mortalité postopératoires ni de taux élevé de toxicité tardive. La question maintenant est de savoir si la radiothérapie a toujours sa raison d'être avec l'optimisation de la chirurgie. Le taux moyen de récurrence locale, d'après l'ensemble des essais cliniques déclarés, s'élève à $29 \%$ avec les techniques traditionnelles tandis que, selon des séries obtenues en établissement, ce chiffre chute à $10 \%$ avec la chirurgie optimale. Il reste cependant des questions sans réponse : les doses de radiothérapie doivent-elles être fractionnées normalement ou superfractionnées? qui est candidat au traitement?

Key Words: Perioperative radiotherapy; Rectal cancer

$\mathrm{T}$ he primary treatment for rectal cancer is surgery. The overall five-year survival figures have slowly improved during the past decades, and currently approximately $50 \%$ of all patients with rectal cancer will survive (1). Approximately 20\% of patients have already developed distant metastases or have a locally inoperable cancer at the time of diagnosis. The two main reasons for a fatal outcome in patients who undergo curative surgery are occult distant metastases not found at surgery and an often unacceptably high local recurrence rate. The average local recurrence rate reported from controlled trials worldwide is $29 \%$. The majority of local recurrences are due to inappropriate surgery, with a positive circumferential margin, with microscopic tumour foci left behind (2,3). Even if surgery is done

This mini-review was prepared from a presentation made at the World Congress of Gastroenterology, Vienna, Austria, September 6 to 11, 1998 Colorectal Unit, University Hospital, S-751 85 Uppsala, Sweden

Correspondence and reprints: Dr Lars Påhlman, Colorectal Unit, University Hospital, S-751 85 Uppsala, Sweden. Telephone +46-18-6114675, fax+46-18-6114632, e-mail lars.pahlman@kirurgi.uu.se

Received for publication October 5, 1999. Accepted October 6, 1999 
TABLE 1

Pelvic recurrence after a combination of surgery and radiotherapy in rectal carcinoma (controlled trials with patients who underwent surgery alone)

\begin{tabular}{|c|c|c|c|c|c|c|}
\hline & Irradiation & & Surgery alone & Surgery plus radiotherapy & & \\
\hline Author (reference) & $\begin{array}{l}\text { Dose (Gy)/ } \\
\text { number of } \\
\text { fractions }\end{array}$ & $\begin{array}{l}\text { LQ } \\
\text { time }\end{array}$ & $\begin{array}{l}\text { Number of local } \\
\text { recurrences/total (\%) }\end{array}$ & $\begin{array}{l}\text { Number of local } \\
\text { recurrences/total (\%) }\end{array}$ & $\mathbf{P}$ & $\begin{array}{c}\text { Reduction } \\
\text { in local } \\
\text { failure rates (\%) }\end{array}$ \\
\hline \multicolumn{7}{|l|}{ Preoperative } \\
\hline Rider et al (12) & $5 / 1$ & 7.5 & $*$ & - & - & - \\
\hline \multirow[t]{2}{*}{ Duncan et al (13) } & $5 / 1$ & 7.5 & + & - & - & - \\
\hline & $20 / 10$ & 20.4 & + & - & - & - \\
\hline Goldberg et al (14) & $15 / 3$ & 22.5 & $51 / 210^{\ddagger}(24)$ & $31 / 185^{\ddagger}(17)$ & NS & 29 \\
\hline Roswit et al (15) & $31.5 / 18$ & 26.8 & $*$ & & & \\
\hline Horn et al (16) & $31.5 / 18$ & 26.8 & 31/131 (24) & 24/138 (17) & NS & 29 \\
\hline Higgins et al (17) & $25 / 10$ & 27.5 & $32 / 87^{\S}(37)$ & $27 / 93^{\S}(22)$ & NS & 22 \\
\hline Marsh et al (18) & $20 / 4$ & 30.0 & 58/141 (41) & 26/143 (18) & $<0.01$ & 63 \\
\hline Gérard et al (19) & $34.5 / 15$ & 35.2 & 49/175 (28) & 24/166 (14) & $<0.01$ & 50 \\
\hline MRC- $2^{\pi}(20)$ & $40 / 20$ & 36.0 & 50/132 (38) & $41 / 129(32)$ & NS & 16 \\
\hline SRCSG (21) & $25 / 5$ & 37.5 & $120 / 425(28)$ & 61/424 (14) & $<0.01$ & 50 \\
\hline SRCT (22) & $25 / 5$ & 37.5 & $131 / 557(24)$ & $51 / 553(9)$ & $<0.001$ & 61 \\
\hline \multicolumn{7}{|l|}{ Postoperative } \\
\hline Bentzen et al (23) & $50 / 25$ & 35.4 & $57 / 250(23)$ & 46/244 (19) & NS & 17 \\
\hline MRC-3 (24) & $40 / 20$ & 36.0 & 69/235 (29) & 46/234 (20) & $<0.01$ & 31 \\
\hline GITSG (25) & $40-48 / 22$ & 36.0 & 27/106 (25) & 15/96 (16) & NS & 36 \\
\hline Fisher et al (26) & $46.5 / 26$ & 39.3 & 45/184 (24) & 30/184 (16) & NS & 33 \\
\hline Arnaud et al (27) & $46 / 23$ & 40.8 & 30/88 (34) & $25 / 84(30)$ & NS & 13 \\
\hline Treurniet-Donker et al (28) & 3) $50 / 25$ & 43.8 & 28/84 (33) & 21/88 (24) & NS & 41 \\
\hline
\end{tabular}

Trials are compiled according to biological dose-volume. ${ }^{*}$ Not reported; ${ }^{\dagger}$ Only actuarial data reported, with no difference between groups; ${ }^{\ddagger}$ Outpatients only reported; ${ }^{\S}$ Autopsy series only reported; "Only tethered tumours. GITSG Gastrointestinal Tumor Study Group; LQ Linear quadratic formula; MRC Medical Research Council; NS Not significant (P>0.05); SRCSG Swedish Rectal Cancer Study Group; SRCT Swedish Rectal Cancer Trial

in a correct way, some areas with microscopic tumour foci are not suitable for surgery due to increased morbidity but are small enough to be eradicated by radiotherapy. Therefore, the rationale for combining surgery and radiotherapy is that surgery removes the tumour bulk and radiotherapy eradicates tumour cells in the periphery.

The present review focuses on the efficacy of radiotherapy in reducing the local recurrence rate, improving survival and reducing adverse effects, both acute and late, and on the rationale of using radiotherapy provided that surgery is optimized. Another important topic is distinguishing the different treatment options for resectable ( $\mathrm{T} 1$ to $\mathrm{T} 3$ ) and nonresectable (T4) tumours.

\section{RADIOTHERAPY IN NONRESECTABLE (T4) TUMOURS}

It is extremely important to diagnose nonresectable tumours preoperatively. The rationale for using radiotherapy in cases such as this is to shrink the tumour to such an extent that curative surgery is possible. It is, therefore, very important to identify this group of patients because, at surgery, it is too late to discover that the tumour should have had preoperative radiotherapy to become operable. In patients with a tumour that is considered nonresectable at diagnosis, preoperative radiotherapy treatment to a dose of
50 Gy, given with conventional fractionation (1.8 to 2.0 fractions), is recommended. There is no real controversy about this type of treatment. Most surgeons are aware of the beneficial effect of preoperative radiotherapy in this patient group with nonresectable tumours - but it is important to identify those patients. Experimental data indicate that radiotherapy is often combined with chemotherapy in this patient category $(4,5)$. However, there are still very few evidence-based data supporting this combined treatment, although theoretically it is tempting to combine chemotherapy and radiotherapy. The only thing that is known for sure is that toxicity increases when chemotherapy is used $(5,6)$. Therefore, there is an urgent need for trials exploring the hypothesis that chemoradiotherapy is better than radiotherapy alone in terms of resectability in the short term, and in terms of survival.

There is no real controversy about this type of treatment. It is more important to discuss adjuvant treatment.

\section{ADJUVANT TREATMENT}

The rationale for using radiotherapy in addition to surgery is the high local recurrence rate, which has been reported in numerous series worldwide. The reported rate ranges from less than $10 \%$ to more than $50 \%(7-11)$. This substantial variation is difficult to explain, but factors such as patient 
selection and definition of radicality, as well as local recurrence, follow-up routines and skill of the surgeons, are well known. An interesting finding is that, in all controlled, randomized trials using adjuvant radiotherapy (pre- or postoperatively), the average local recurrence rate is $29 \%$, with a range of $23 \%$ to $46 \%(12-28)$ (Table 1). Although this figure is very high, it reflects the real figure, because in randomized trials, all patients with a resected tumour were reported (R0, R1 and $\mathrm{R} 2$ resections), which actually is the actual situation. In reports with excellent results, often only patients with an $\mathrm{R} 0$ resection have been presented.

Effect on local recurrence rate: As seen in Table 1, where all trials have been compiled according to the dose intensity, there is a clear dose-response relation in the reduction of the local recurrence rate. This relation is most predominant in trials in which preoperative radiotherapy was used, where a higher dose increased the reduction of the local recurrence rate. As shown in Table 1, which displays all controlled, randomized trials, when the same dose was used, the effect on the local recurrence rate was far better with preoperative radiotherapy than with postoperative radiotherapy. The question of timing - pre- or postoperative therapy - has been addressed in only one randomized trial in which patients were allocated to preoperative or postoperative radiotherapy $(29,30)$. In that trial, the Uppsala trial, preoperative radiotherapy was superior to postoperative irradiation in reducing local recurrence rates. Thus, preoperative radiotherapy is more dose-effective than postoperative radiotherapy. This outcome is rather difficult to explain, but two important factors can contribute to this difference. First, radiotherapy needs oxygen to work, and in a preoperative setting, the tissue is well oxygenated. Second, the delay between surgery and postoperative radiotherapy is often more than four weeks in trials using postoperative radiotherapy, and most patients start the radiotherapy after six weeks. This delay probably enhances repopulation of tumour cells, resulting in a tumour burden that is too large to eradicate $(31,32)$.

Effect on survival: It is unlikely that radiotherapy to the pelvic region has any impact on occult metastases. However, the local recurrence is often the first recurrence of rectal cancer, and if the local recurrence rate could be better controlled with additional radiotherapy, an effect on survival would be possible. This has been shown in a study among surgeons, which demonstrated that surgeons who had a low local recurrence rate in their series of patients achieved better survival rates than surgeons who had a high local recurrence rate (33). No trial with postoperative radiotherapy has shown an effect on survival, probably because the reduction in the local recurrence rate has not been high enough. After preoperative radiotherapy, on the other hand, an effect on cancer-specific survival has been shown in several trials using high dose radiotherapy $(18,19,34,35)$. The largest trial of preoperative radiotherapy, the Swedish Rectal Cancer Trial (35), not only showed an effect on cancer-specific survival, but also showed an effect on overall survival. In that trial, $48 \%$ of patients undergoing surgery alone were alive after five years compared with $58 \%$ in the group of patients who received preoperative radiotherapy and surgery.

Preoperative chemoradiotherapy has not been proven to achieve a better effect on survival, despite its theoretical advantages $(4,5)$, because no trial has studied radiotherapy and chemotherapy in an adjuvant preoperative setting. However, there is strong evidence that postoperative radiotherapy combined with chemotherapy results in a survival benefit of almost the same magnitude as that with preoperative radiotherapy alone $(25,36-38)$. The problem with combining radiotherapy and chemotherapy is the increased toxicity $(6,39)$.

How to use additional radiotherapy is a matter of national preferences and tradition. In Scandinavia and the United Kingdom, as in many centres in Europe, preoperative radiotherapy is used, whereas in the United States and Canada, postoperative chemoradiotherapy is the recommended treatment (40).

\section{TOXICITY OF ADJUVANT RADIOTHERAPY}

If adjuvant radiotherapy is recommended as the standard treatment, the important balance between the effect on tumour cell killing and the side effects of radiotherapy has to be considered. Radiotherapy has adverse effects in both the acute and subacute phases, which has been relatively well studied, but it also induces late toxicity, which has not been well explored. It is very important to evaluate late toxicity because it is long time survivors who experience this type of toxicity.

Acute toxicity: Only preoperative radiotherapy could increase morbidity in the immediate postoperative period. Data from numerous trials have shown that there is an increase in perineal wound sepsis in patients having had preoperative radiotherapy and surgery with an abdominal perineal excision $(19-21,41)$. However, in the same trials, no adverse effects of anastomotic healing were shown; experimental data indicate that radiotherapy does not affect anastomotic healing and that the anastomotic integrity after a low anterior resection does not seem to be influenced by preoperative radiotherapy (42).

Data regarding compliance and acute tolerability indicate that preoperative radiotherapy is more tolerable than postoperative radiotherapy. This difference in acute toxicity was noticed in the only trial that compared preoperative and postoperative radiotherapy (43). In the Adjuvant X-ray Infusion Study (AXIS), patients were randomly assigned to radiotherapy before surgery, but pre- or postoperative radiotherapy was optional (44). In the group of patients who underwent preoperative radiotherapy, $96 \%$ received the intended treatment compared with only $56 \%$ of patients who underwent postoperative radiotherapy. This figure indicates that some patients who are eligible for radiotherapy do not receive the treatment if postoperative regimens are used.

A more important finding in the literature is of postoperative mortality. Two trials have demonstrated an increased risk of postoperative mortality after preoperative 
radiotherapy; this increased risk was predominantly seen in elderly patients and patients with generalized disease. In both of these trials, large target volumes were used $(14,45)$. However, data from the Swedish Rectal Cancer Trial indicate that preoperative radiotherapy can be delivered without an increase in postoperative mortality, provided that radiotherapy is optimized (41).

Another important finding from the Swedish trials is that of acute neurogenic pain, which has been noticed in the gluteal area and along the hamstrings. In some patients, this radiotherapy-induced neuropathy has led to the inability to walk and persistent pain (46). This acute neuropathy has only been seen in patients in whom 5 Gy fractions were used. The exact mechanism of this pain is very unclear, but with hyperfractionated radiotherapy, it is even more important that radiotherapy be optimized. The dose used in the Swedish trial (five doses of 5 Gy during one week) is radiobiological; this treatment is rather odd but very cost effective and may be suboptimal (see below).

In the Dutch trial, in which total mesorectal excision (TME) surgery was mandatory, an increased risk of adverse side effects and postoperative mortality was seen. An interim report showed no increase in postoperative mortality after TME surgery and preoperative radiotherapy, but an increased infection rate among irradiated patients (47). Data from the literature indicate that radiotherapy has to be optimized and that, with three- or four-field technique, there is no risk of postoperative mortality, whereas there is a substantial risk if a two-field technique is used, where a larger target volume is given to the patient (41). In the Swedish Rectal Cancer Trial, the method of giving radiotherapy was strictly described. The radiation technique used for patients from Stockholm who were included in the trial did not include appropriate lead blocking. Figures reported in the Stockholm II trial, which predominantly comprised patients from the Swedish Rectal Cancer Trial, showed a slight increase in postoperative mortality, which might be an effect of inappropriate lead blocking (48).

Late radiation-associated toxicity: Unfortunately, very little has been published regarding the relationship between late toxicity to adjuvant radiotherapy and rectal cancer. Most data are derived from the Swedish trials, where $25 \mathrm{~Gy}$ in one week has been used preoperatively. Trials that used the more common treatment in the United States - postoperative chemoradiotherapy to a total dose of 45 to $50 \mathrm{~Gy}$ - have not explored the late toxicity to the same extent. However, it is very important that the late adverse effects are reported after both preoperative and postoperative radiotherapy.

Intestinal obstruction: The risk of having a small bowel obstruction after surgery for rectal cancer is estimated to be $5 \%$ to $10 \%$. If preoperative radiotherapy is used with an optimized technique, this incidence is not dramatically increased (30). However, if a larger target volume is used or if postoperative radiotherapy is used, the risk is substantially increased $(30,48)$. For postoperative radiotherapy, the increased risk of small bowel obstruction is rather easy to explain because small bowel loops can be stacked into the lesser pelvis after surgery and are thus situated in the target volume.

Bowel function: It is easy to understand that bowel function after an anterior resection can be affected after postoperative radiotherapy because the distal part of the rectum is irradiated as well as the large bowel, which is anastomosed down to the rectal stump or anal canal. Moreover, there are parts of the small bowel that are irradiated both pre- and postoperatively, and this can cause slight damage to the intestinal mucosa, resulting in a high risk of more loose stool. There are some reports that patients with postoperative radiotherapy have experienced a clear change in bowel function in the long run $(49,50)$. Data have also indicated that preoperative radiotherapy has similar effects on adverse effects and bowel function (51), and in a questionnaire study from the Swedish Rectal Cancer Trial, bowel function was found to be impaired, despite that most of the irradiated part of the rectum had been removed at surgery (52). One explanation may be that the sphincters were irradiated according to the protocol, and a clear recommendation is that, if preoperative radiotherapy is going to be used, the sphincters should be excluded if it is suitable in terms of appropriate cancer treatment.

Damage to the pelvic organs: With radiotherapy to the pelvis, several organs are in danger of being damaged. However, very little has been reported about bladder damage due to adjuvant radiotherapy, and the risk of having adverse bladder function after pre- or postoperative radiotherapy appears to be small (48). The Stockholm group reported an increased risk of pelvic fractures and fractures of the femoral neck (48). Interestingly, according to the Stockholm protocol, no appropriate lead blocking was used, hindering radiotherapy to the femoral neck and sacrum; this is one probable explanation for why increased fractures were found in this group. A recent surveillance of adverse effects in the Swedish Rectal Cancer Trial has not found the same incidence of fractures, although the same dose has been used, but with a different radiation technique and appropriate lead blocking (Dahlberg, personal communication).

\section{IS ADJUVANT RADIOTHERAPY NEEDED FOR THE TREATMENT OF RECTAL CANCER?}

So far, all trials published with a control arm have reported a local average recurrence rate of rectal cancer of $29 \%$ (Table 1), indicating that the surgical procedure was suboptimal. Recent data indicate that, if surgery is optimal and a good circumferential resection can be done (often a TME) the local recurrence rate is substantially decreased. Therefore, one can argue whether radiotherapy is really needed in patients who have optimal surgery. Only one trial has addressed this topic - the Dutch TME trial, in which surgeons had to be accredited as an appropriate TME surgeon. This trial was completed in January 2000. A total of 1861 patients were included in the randomized study, but no data regarding recurrence rate or survival are yet avail- 
able. Data from single centre studies from Norway indicate that it is possible to reduce the local recurrence rate from approximately $30 \%$ to just under $10 \%$ if surgery is optimized (Myrvold, personal communication). If preoperative radiotherapy ( 25 Gy in one week) is used together with optimized surgery, it appears that the reduction in local recurrence rate is of even higher magnitude than has been seen in randomized trials. In the Stockholm area, in a population-based, nonrandomized study, the overall local recurrence rate was $5.6 \%$ after the introduction of TME surgery. The recurrence rates among patients having had preoperative radiotherapy or surgery alone were $2 \%$ and $10 \%$, respectively, indicating that radiotherapy affects the local recurrence rate, even if surgery is optimized (53). Data from Uppsala, Sweden revealed a recurrence rate of $3 \%$ when TME surgery was combined with preoperative radiotherapy (25 Gy in one week) (54).

\section{WHAT TYPE OF RADIOTHERAPY SHOULD BE USED?}

Most data from the literature indicate that preoperative radiotherapy is more dose effective than postoperative radiotherapy (55). Therefore, in Europe, preoperative radiotherapy is used. The main question is whether the Swedish radiotherapy schedules of five doses of 5 Gy during one week, with surgery the following week, or a more conventional radiotherapy, with 1.8 to $2 \mathrm{~Gy}$ fractions over a five-week period, should be used. No trial has compared those two treatment schedules, but the effect on local recurrence rates is probably the same. A more important question is whether adverse effects might be higher if five doses of 5 Gy were used. This question is addressed in a new Swedish trial. The choice of a one-week treatment instead of a five-week treatment is more a matter of economics because the one-week treatment is less resource demanding, and it must be up to each centre to choose the appropriate treatment.

Another important question is whether radiotherapy should be combined with chemotherapy. Again, there are no good data to support that chemoradiotherapy is superior to radiotherapy alone in an adjuvant setting. A European Organization for Research and Treatment of Cancer trial is currently testing this hypothesis. The patients receive preoperative radiotherapy with conventional fractionation but are randomly allocated to either receive or not receive concomitant chemotherapy. That trial evaluated efficacy as well as toxicity.

It has been claimed that the number of patients with preserved sphincters will increase if preoperative chemoradiotherapy is used (56); the rationale is that it is a more effective treatment, and if the interval from end of radiotherapy to surgery is prolonged, down-staging will increase the chance of preserving the sphincter. This has been studied in a French trial (57) in which all patients received chemoradiotherapy but were randomly assigned to have surgery immediately after irradiation or after six weeks. More patients had their sphincters preserved if surgery was delayed ( $76 \%$ versus $68 \%$, respectively). However, the surgeons were asked before radiotherapy started whether they could perform an anterior resection. The overall recurrence rate was $9 \%$, and in the group of patients having an anterior resection where a sphincter-preserving operation did not seem possible initially, the local recurrence rate was $12 \%$ (57). The numbers were small in this trial, but the data must be taken seriously, and it might be dangerous to rely on the downstaging effect caused by preoperative chemoradiotherapy and change surgery from an abdominoperineal procedure to a sphincter-persevering operation.

\section{CONCLUSIONS}

Results from trials worldwide indicate that adjuvant preoperative radiotherapy is more dose effective than postoperative radiotherapy in terms of reducing the local recurrence rate. Only preoperative radiotherapy alone has shown a survival benefit, but postoperative radiotherapy has shown an effect on survival when combined with chemotherapy. Three main questions need to be answered. One question is regarding the type of radiotherapy - should the Swedish concept of five doses of 5 Gy for one week or the more traditional five-week period of radiotherapy be used. The other unsolved question is whether chemotherapy should be given concomitantly to radiotherapy. The third unanswered question is whether radiotherapy should be used if surgery is optimized. This is a very difficult question to answer. Ongoing trials might answer the question of whether there is a place for radiotherapy in all patients with rectal cancer or whether it should be used more selectively.

\section{REFERENCES}

1. Stenbeck M, Rosén M, Holm L-E. Cancer survival in Sweden during three decades 1961-1991. Acta Oncol 1995;34:881-91.

2. Adam IJ, Mohamdee MO, Martin IG, et al. Role of circumferential margin involvement in the local recurrence of rectal cancer. Lancet 1994;344:707-11.

3. Ny IOL, Luk ISC, Yuen ST, et al. Surgical lateral clearance in resected rectal carcinomas, a multivariate analysis of clinicopathological features. Cancer 1993;71:1972-6.

4. Lawrence TS, Davis MA, Maybaum J. Dependence of 5-fluorouracilmediated radiosensitization on DNA-directed effects. Int J Radiat Oncol Biol Phys 1994;29:519-23.

5. Tannock F. Treatment of cancer with radiation and drugs. J Clin Oncol 1996;14:3156-74.

6. Overgaard M, Bertelsen K, Dalmark M, et al. A randomized feasibility study evaluating the effect of radiotherapy alone or combined with 5-fluorouracil in the treatment of locally or inoperable colorectal carcinoma. Acta Oncol 1993;32:547-53.

7. MacFarlane JK, Ryall RDH, Heald RJ. Mesorectal excision for rectal cancer. Lancet 1993;341:457-60.

8. Enker WE. Total mesorectal excision - the new golden standard of surgery for rectal cancer. Ann Med 1997;29:127-33.

9. Gunderson L, Sosin H. Areas of failure found at reoperation (second or symptomatic look) following 'curative surgery' for adenocarcinoma of the rectum. Cancer 1974;34:1278-92.

10. Phillips RK, Hittinger R, Blesovsky L, Fry JS, Fielding LP. Local recurrence following 'curative' surgery for large bowel cancer: I. The overall picture. Br J Surg 1984;71:12-6.

11. Påhlman L, Glimelius B. Local recurrences after surgical treatment for rectal carcinoma. Acta Chir Scand 1984;150:331-5.

12. Rider WD, Palmer JA, Mahoney LJ, Robertson CT. Preoperative irradiation in operable cancer of the rectum: Report of the Toronto trial. Can J Surg 1977;20:335-8. 
13. Duncan W, Smith AN, Freedman LS, Alderson MR, Arnott SJ, Bleehen NM. The evaluation of low dose pre-operative X-ray therapy in the management of operable rectal cancer; results of a randomly controlled trial. Br J Surg 1984;71:21-5.

14. Goldberg PA, Nicholls RJ, Porter NH, Love S, Grimsey JE. Long-term results of a randomised trial of short-course low-dose adjuvant preoperative radiotherapy for rectal cancer: Reduction in local treatment failure. Eur J Cancer 1994;30A:1602-6.

15. Roswit B, Higgins G, Keehn R. Preoperative irradiation for carcinoma of the rectum and rectosigmoid colon: Report of a National Veterans Administration randomized study. Cancer 1975;35:1597-602.

16. Horn A, Halvorsen JF, Dahl O. Preoperative radiotherapy in operable rectal cancer. Dis Colon Rectum 1990;33:823-38.

17. Higgins G, Humphrey E, Dwight R, Roswit B, Lee L, Keehn R. Preoperative radiation and surgery for cancer of the rectum. VASOG Trial II. Cancer 1986;58:352-9.

18. Marsh PH, James RD, Schofield PF. Adjuvant preoperative radiotherapy for locally advanced rectal carcinoma. Results of a prospective, randomized trial. Dis Colon Rectum 1994;37:1205-14.

19. Gérard A, Buyse M, Nordlinger B, et al. Preoperative radiotherapy as adjuvant treatment in rectal cancer. Ann Surg 1988;208:606-14.

20. Medical Research Council Rectal Cancer Working Party. Randomised trial of surgery alone versus radiotherapy followed by surgery for potentially operable locally advanced rectal cancer. Lancet 1996;348:1605-10

21. Stockholm Rectal Cancer Study Group. Preoperative short-term radiation therapy in operable rectal carcinoma. A prospective randomized trial. Cancer 1990;66:49-55.

22. Swedish Rectal Cancer Trial. Local recurrence rate in a randomized multicentre trial of preoperative radiotherapy compared to surgery alone in resectable rectal carcinoma. Eur J Surg 1996;162:397-402.

23. Bentzen SM, Balslev I, Pedersen M, et al. Time to loco-regional recurrence after resection of Dukes' B and C colorectal cancer with or without adjuvant postoperative radiotherapy. Br J Cancer 1992;65:102-7.

24. Medical Research Council Rectal Cancer Working Party. Randomised trial of surgery alone versus surgery followed by radiotherapy for mobile cancer of the rectum. Lancet 1996;348:1610-4.

25. Gastrointestinal Tumor Study Group. Prolongation of the disease-free interval in surgically treated rectal carcinoma. N Engl J Med 1985;312:1464-72

26. Fisher B, Wolmark N, Rockette H, et al. Postoperative adjuvant chemotherapy or radiation therapy for rectal cancer: Results from NSABP Protocol R-01. J Natl Cancer Inst 1988;80:21-9.

27. Arnaud JP, Nordlinger B, Bosset JF, et al. Radical surgery and postoperative radiotherapy as combined treatment in rectal cancer. Final results of a phase IIII study of the European Organization for Research and Treatment of Cancer. Br J Surg 1997;84:352-7.

28. Treurniet-Donker AD, van Putten WLJ, Wereldsma JCJ, et al. Postoperative radiation therapy for rectal cancer. Cancer 1991;67:2042-8.

29. Påhlman L, Glimelius B, Graffman S. Pre- versus postoperative radiotherapy in rectal carcinoma: an interim report from a randomized multicentre trial. Br J Surg 1985;72:961-6.

30. Frykholm G, Glimelius B, Påhlman L. Pre- or postoperative irradiation in adenocarcinoma of the rectum: Final treatment results of randomized trial and evaluation of late secondary effects. Dis Colon Rectum 1993;36:564-72.

31. Withers HR, Taylor JMG, Maciejewski B. The hazard of accelerated tumor clonogen repopulation during radiotherapy. Acta Oncol 1988;27:131-46.

32. Glimelius B, Isacsson U, Jung B, Påhlman L. Radiotherapy in addition to radical surgery in rectal cancer - evidence for a dose-response effect favouring preoperative treatment. Int J Radiat Oncol Biol Phys 1997;37:281-7.

33. Hermanek P, Wiebelt H, Staimmer D, Riedl S. Prognostic factors of rectum carcinoma - experience of the German multicentre study SGCRC. Tumori 1995;81(Suppl):60-4.

34. Stockholm Colorectal Cancer Study Group. Randomized study on preoperative radiotherapy in rectal carcinoma. Ann Surg Oncol 1996;3:423-30

35. Swedish Rectal Cancer Trial. Improved survival with preoperative radiotherapy in resectable rectal cancer. N Engl J Med 1997;336:980-7.
36. Krook JE, Moertel CG, Gunderson LL, et al. Effective surgical adjuvant therapy for high-risk rectal cancer. N Engl J Med 1991;324:709-15.

37. Tveit KM, Gudvog I, Hagen S, et al. Improved treatment results in rectal cancer by postoperative radiotherapy and 5 -fluorouracil. Eur J Cancer 1995;31A:146. (Abst)

38. Rockette H, Deutsch M, Petrelli N, et al. Effect of postoperative radiation therapy (RTX) when used with adjuvant chemotherapy in Dukes' B and C rectal cancer: Results from NSABP R-02. ASCO 1994;13:193. (Abst)

39. Boulis-Wassif S. Ten years' experience with a multimodality treatment of advanced stages of rectal cancer. Cancer 1983;45:2017-24.

40. NCI Clinical announcement. Adjuvant therapy of rectal cancer, 14:e mars, 1991.

41. Swedish Rectal Cancer Trial. Initial report from a Swedish multicentre study examining the role of preoperative irradiation in the treatment of patients with resectable rectal carcinoma. Br J Surg 1993;80:1333-6.

42. Bubrik MP, Rolfmeyers ES, Schauer RM, et al. Effects of high-dose and low-dose preoperative irradiation on low anterior anastomosis in dogs. Dis Colon Rectum 1982;25:406-15.

43. Påhlman L, Glimelius B. Pre- or postoperative radiotherapy in rectal carcinoma: a report from a randomized multicenter trial. Ann Surg 1990;211:187-95

44. James R, on behalf of the AXIS Collaborators, MRC Clincial Trials Unit. Perioperative radiotherapy (RT) and intraportal 5-fluorouracil (5-FU;PVI) in the adjuvant treatment of colorectal cancer. Adjuvant X-ray Infusion Study (AXIS) trial. Dis Colon Rectum 1999;42:A63. (Abst)

45. Holm T, Rutqvist LE, Johansson H, Cedermark B. Postoperative mortality in rectal cancer treated with or without preoperative radiotherapy: causes and risk factors. Br J Surg 1996;83:964-8.

46. Frykholm-Jansson G, Sintorn K, Montelius A, Jung B, Påhlman L, Glimelius B. Acute lumbosacral plexopathy after preoperative radiotherapy in rectal carcinoma. Radiother Oncol 1996;38:121-30.

47. Kapiteijn E, Kranenberg EK, Steup WH, et al. Total mesorectal excision (TME) with or without preoperative radiotherapy in the treatment of primary rectal cancer. Eur J Surg 1999;165:410-22.

48. Holm T, Singnomklao T, Rutqvist L, Cedermark B. Adjuvant preoperative radiotherapy in patients with rectal carcinoma. Adverse effects during long term follow-up of two randomized trials. Cancer 1996:78;968-76.

49. Lewis WG, Williamson MER, Stephenson BM, et al. Potential disadvantages of postoperative adjuvant radiotherapy after anterior resection for rectal cancer: a pilot study of sphincter function, rectal capacity and clinical outcome. Int J Colorectal Dis 1995;10:133-7.

50. Kollmorgen CF, Meagher AP, Wolf BG, Pemberton JH, Martenson JA, Ilstrup DM. The long-term effect of adjuvant postoperative chemoradiotherapy for rectal carcinoma on bowel function. Ann Surg 1994;220:676-82.

51. Graf W, Ekström K, Glimelius B, Påhlman L. A pilot study of factors influencing bowel function after colorectal anastomosis. Dis Colon Rectum 1996;39:593-600.

52. Dahlberg M, Glimelius B, Graf W, Påhlman L. Preoperative irradiation affects the functional results after surgery for rectal cancer: results from a randomized study. Dis Colon Rectum 1998;41:543-51.

53. Martling AL, Holm T, Rutqvist LE, Moran BJ, Heald RJ, Cedemark B. Effect of a surgical training programme on outcome of rectal cancer in the County of Stockholm. Stockholm Colorectal Cancer Study Group, Basingstoke Bowel Cancer Research Project. Lancet 2000;356:93-6

54. Dahlberg M, Glimelius B, Påhlman L. Changing strategy for rectal cancer is associated with improved outcome. Br J Surg 1999;86:379-84.

55. Glimelius B, Påhlman L. Perioperative radiotherapy in rectal cancer Acta Oncol 1999;38:23-32.

56. Minsky BD, Cohen AM, Enker WE, Pary P. Sphincter preservation with preoperative radiation therapy and coloanal anastomosis. Int J Radiat Oncol Biol Phys 1995;31:553-9.

57. Francois $\mathrm{Y}, \mathrm{Nemoz} \mathrm{CJ}$, Baulieux J, et al. Influence of the interval between preoperative radiation therapy and surgery on downstaging and on the rate of sphincter-sparing surgery for rectal cancer: The Lyon R90-01 randomized trial. J Clin Oncol 1999;17:2396-402. 


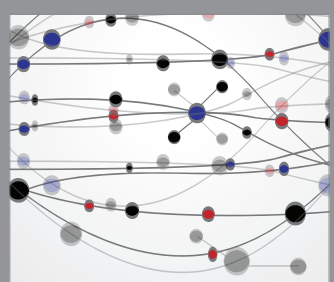

The Scientific World Journal
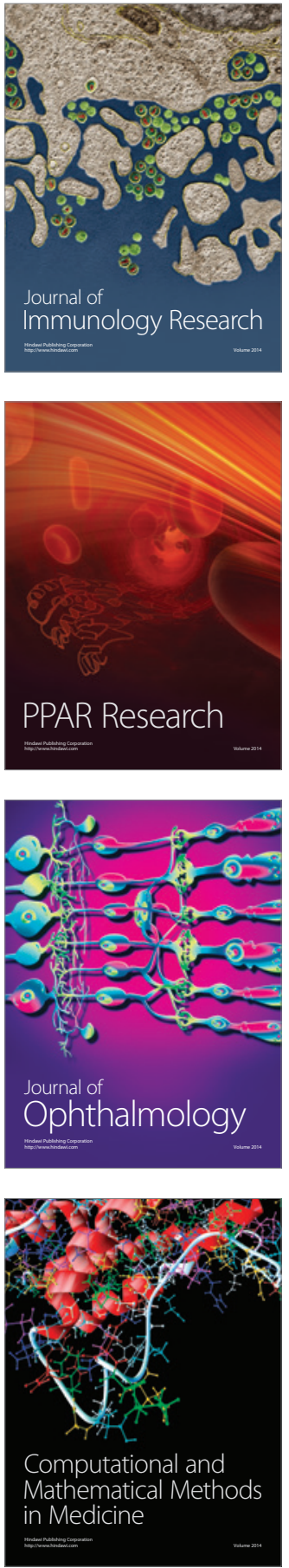

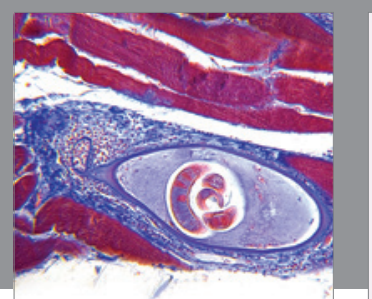

Gastroenterology Research and Practice

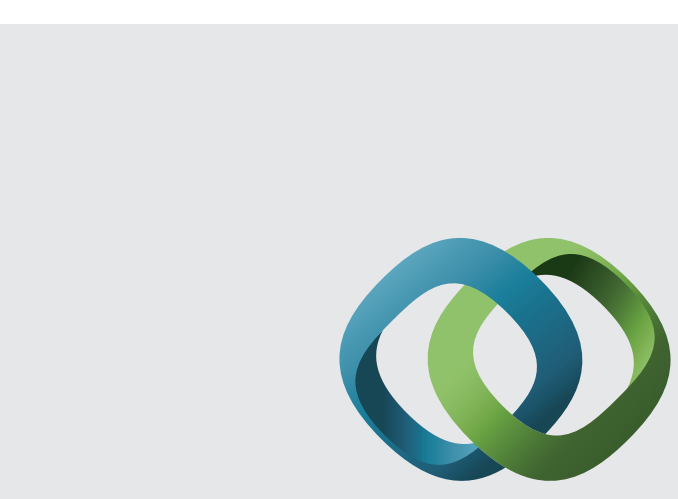

\section{Hindawi}

Submit your manuscripts at

http://www.hindawi.com
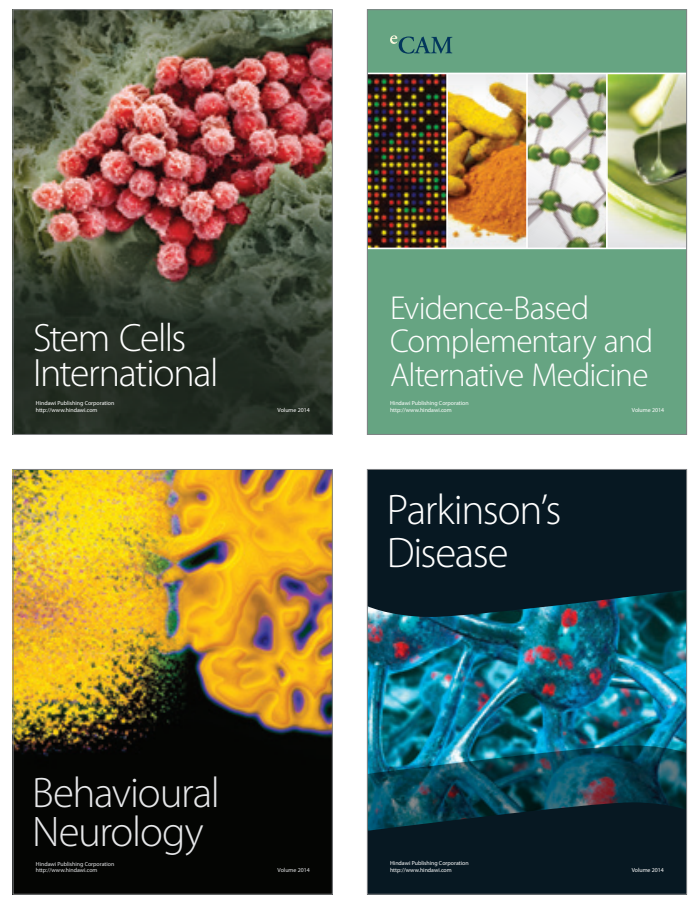
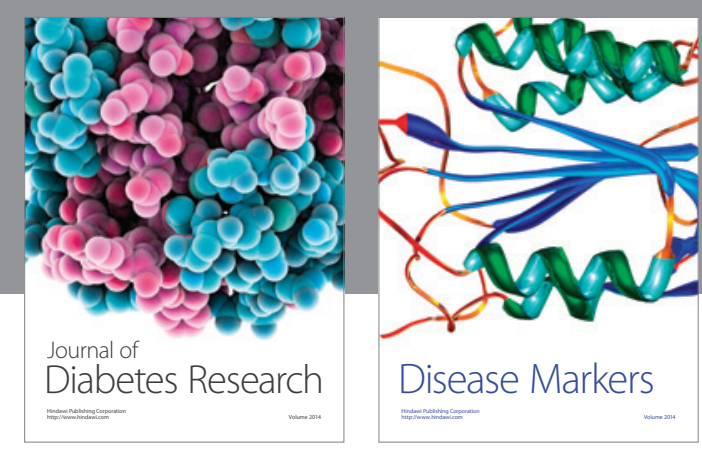

Disease Markers
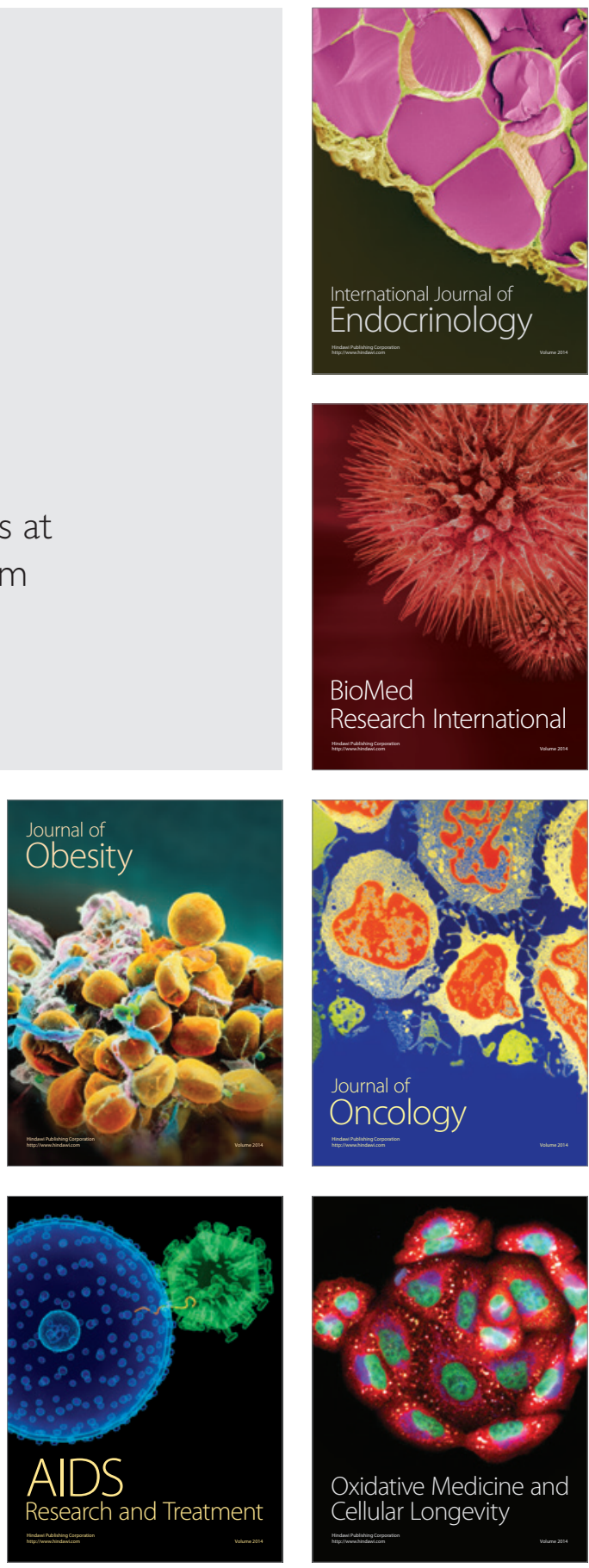